\title{
Crisis Management and Its Process in Organization
}

\author{
1,2 Mohsen Karimi Mehr \\ ${ }_{2}^{2}$ Ramezan Jahanian
}

${ }^{1}$ Department of Education, Alborz Science and Research Branch, Islamic Azad University, Karaj, Iran ${ }^{2}$ Department of Education, Karaj Branch, Islamic Azad University, Karaj, Iran *Corresponding author: ramezan.jahanian@kiau.ac.ir

\section{Doi:10.5901/mjss.2016.v7n5s1p143}

\section{Abstract}

The issue of crisis management is discussed in various fields. Organizations as a key component of today's society are not exempt from this important issue. This article examined the types of crises in the organization. Pioneer managers had tried to use the findings of organization management crisis and integrating it with the achievements of strategic management and management control systems to avoid dangerous unforeseen waves. At first, article defined institutional crisis, then by expression of the crisis, the definition of crisis management and its necessity, led to talk the models of management crisis and eventually suggests a strategic framework and six major steps that can be taken to prepare proposes in an organization crisis.

Keywords: management crisis, process, organization

\section{Introduction}

The traditional approach to crisis management believes that crisis management is quench the fire; which means that the the crisis managers sit expected deterioration and after its destruction, and try to limit the damage arising from failure. Recently, though, attitudes to these words have changed. According to the latter sense, always a set of plans and action plans should be regulated to deal with possible future developments within the organizations set. Also, managers should think about possible future events and prepared to deal with unforeseen events they attend; thus, crisis management emphasizes on the need to anticipate and prepares dealing with those issues regular internal and external stresses, seriously reputation, profitability or organization life threatening. It should be noted that the crisis management is different from management public relations (Booth, 1993). "Larry Smith" director of the Institute crisis defines crisis as "a major upheaval in the organization that has widespread media coverage and curious people impact on the issue on ordinary activities and can effect on political, legal, financial and governmental organizations (Jack Gatz, 2004). However, the crisis does not occur by abrupt and are often warning signs that indicate potential problems. Crisis has interesting parallel with a biological model. Gowne Zalz-Hiro and Pratt (1996) suggested that a crisis could be a mechanism similar to the process of birth, growth, maturity and decline or death passing. In Chinese the word "Vijay» (WEIJI) is equivalent with the word of "crisis" and means risk and opportunity (Wei, 2001). In the definition of an institutional crisis, it is better to distinguish the two terms of crisis and disaster (Brent, 2003).

\section{Variety of Crises Divisions}

The first division of the crisis can be divided to individual, group, organizational, and social. Social crises are divided to political, cultural, economic, health, natural (natural causes) and combinations of crises. Usually it is thought that social crises should only be crisis management, but the fact is that monitoring of social crisis first should be foremost to knowledge management. As figures such as growth rate, age composition of the population, the unemployment rate curve plants during growth, growth rate, the percentage of school dropout, technical training and professional capacity, the growth rate of some diseases, the rate of growth of drug addiction rate suicide ages and social status and gender and most of the statistically results indicate a very simple to seek special circumstances and origination of the other hand the inevitable necessity of knowledge management in public services and public administration. Sudden or gradual crisis in terms of their classification means some crises occur suddenly and at a time and have sudden impacts on the internal and external environments that is called ABRUPT CRISES. There is also, cumulative crises. For comparison, sudden crises and gradually six keys are used. Sudden crises arise speed, with little predictability, they are clearly focused, 
manifest, start of a specified event, taking place at a fixed time, and the organization's non-compliance with one or a few aspects the environmental aspect. In comparison, the gradual crises, arise gradual and cumulative, the much anticipated capabilities are not clear, their starting point is of a threshold level, over time, the likelihood of their occurrence get more and organization of non-compliance are created with several aspects of the environment.

\section{Parsons Defines Three Types of Crises as Follows}

\subsection{Immediate crises}

These crises have not any previous warning signs and organizations will also be able to research about them and they are not planning to disposal.

1. Crises that appear gradually, slowly created and can be stopped or restricted by organizational measures.

2. Ongoing crisis: These cries last for weeks, months or even years. Faced strategies with this crisis depends on different situations including time pressures, the extent of control and a massive amount of these events.

The two criteria of threat level, time pressure, and the severity of the events, classify and identify the critical and can be revealed through the site when a phenomenon or a problem can be turned into a crisis. Burnett" using these three criteria and the criteria of reaction or response options, proposed a matrix to classify crisis where 16 houses exist.

"Mytraf View ": he used to classify crises of two ranges. One range specifies internal and external of crises. That crisis happens within the organization or outside the organization. Another range shows technical or social crisis. The weirder such measures, the necessity for readiness of managers to deal with crises caused by them, is more (Spillon, 2002).

\subsection{Crisis and predictors of crisis}

If you want to give definitions of crisis it should be given as proper circumstances defined by individuals. The return point for better or worse or critical juncture. Definitions are short but full of meaning about the crisis. Overall it should be agreed to provide a clear definition of crisis that is extremely difficult and definitions are also all relative. Because it may be a subject to $\mathrm{a}$, organization or community crisis but a crisis in other garment but the fact that the urgent and serious measures should be taken to be in critical condition is more acceptable to all communities because a critical situation is distinct from the normal conditions.

"Kahn and Wighter" presented a comprehensive approach to crisis

1. The turning point in the events and unexpected consequences for his actions.

2. While the immediate reaction of the participants demand.

3. The conditions that create uncertainty.

4. Reduction of control over events.

5. The circumstances in which the available information is severely reduced.

6. Circumstances that increase pressure and stress for employees and communities.

In order to define natural disasters, it can be said that crisis is an accident that is created after the occurrence of natural and human performance suddenly and hardship and difficulty to impose a set or humane society that eliminates the extraordinary need for immediate emergency measures.

\section{The Role of States and Governments in Preventing and Reducing Social and Economic Crises}

Critical management increases knowledge management to public service. For example, the population growth rate in year $X$ demonstrates the need for nursery school, Park gyms, health centers book Fair, recreational centers science laboratory recreational sports centers, movie theater, educational and psychology centers, doctor, and new educational software. Education, knowledge of a generation with satellite, internet, computer, international trade relations, ravel overseas and consort with the children of migrant families are in western countries.

\subsection{Crisis managers}

According to the definitions in the field of crisis management and the crisis that has been focused and what many scholars on have consensus is that the role of crisis management in a short time with the best principles of crisis management. In paragraph 3, a comprehensive plan to rescue the country's crisis management is defined: 
Some of the critical that manager's encounter in a company or organization may include:

- Unmotivated of staff.

- The use of unqualified managers in different parts

- Failure to achieve the objectives of the company or organization

- Dissatisfaction of customers or clients

- Lack of confidence in staff. Portfolio of managers (crisis of confidence)

- Strike

- Financial crises.

- Rules, command, reflex action of non-efficacy and etc.

- Unpredictable events.

In fact, it can be said that the main objective of crisis management is reasonable solution to correct abnormal condition, in a way that basic resources essential for the organization be maintained.

\subsection{Actions that organizations should do in times of crisis are as bellows}

1. The identification and prioritization of the needs of crisis

2. Understanding the factors that caused the crisis to prioritize these factors

3. Providing facilities and grounds need to solve or control or mitigate crisis

4. Choosing appropriate solutions (the best solution)

5. Providing employee involvement, solutions, or suggestions by them (and justifying the staff)

6. The formation of the Crisis Staff

7. The consequences of the crisis to be investigated

8. Since the measures taken to solve the crisis or controlled by members of staff

9. Sometimes the presence of a social worker or psychologist person can also be effective.

10. Identification of centers and institutions that can help in solving the crisis.

\subsection{Crisis management models}

A. The model of Tiri and Mitraf crisis management: Tiri and Mitraf suggested that effective management of organizational crisis, is aside from the kind of crisis, including the crisis in the management of the five stages identified as (1) identify or track marks, (2) preparation and prevention, (3) inhibition of destruction, (4) improvement, (5) learning.

Clearly, the first two stages, is the pre-crisis process and includes pre activity crisis management. For comparison, proactive crisis management has importance for any business organization because the organization in many ways deal with unwanted and unexpected crisis situations and will prepare and place in a favorable position at the time of the crisis. For the emergence of such management three main activities should be done: (1) establish a program for the crisis, (2) crisis management team, and (3) regular training of personnel to deal with the crisis (Rezvani, 2008).

B. The model of proactive versus reactive model: Basically, in a crisis situation, the crisis are seen in two ways including reaction and pre active. Organizations also can ignore warning signs and respond to the crisis and to confront the crisis and its management can prepare in advance. In the first case the consequences of the crisis are not clear but in the latter case not only provides opportunities for crisis management, but could even lead to the disposal crisis. In response model, the decision is taken and adopt a crisis during or after the events, but in pre active models, different forms of decision-makers anticipate the crisis and also plans deal with them. The first step in pre active model, is analyzing pathological crisis that is trying to vulnerabilities in the organization and also identify the factors contributing to the crisis. "Slaughter" has provided model to identify factors contributing to the institutional crisis. In this model, the management and organizational characteristics influence the decision-making efficiency and environmental variables and compete with the effectiveness of the decision, and the move towards crisis forms (Rezvani, 2008). Environmental variables and sudden changes in the environment, include changes in markets, suppliers and providers, economic, political, and social and so on. Management features include capabilities and features of human resources and management skills, leadership styles, they have a strong influence on the decisions and the organization's ability to deal with the crisis. Organizational features include the size of the organization, resources, structure, control and operating procedures and that the impact of crisis situations. 
C. The life cycle of crisis and strategic perspective to it: life cycle of the crisis suggests that any crisis pass through several stages. Classification of the crisis on the basis of its life cycle, in particular the crisis strategies in each of the stages of his life, and even how to stop the crisis useful for administrators (Rezvani, 1387).

\subsection{The necessity of crisis management}

The world is moving towards a global village. We live in a global community that its components interconnected by a complex system. News at the speed of light reaches everywhere. After a few minutes people around the world are aware of it. Media and the public cannot wait to hear the facts and accurate news and explanations are necessary. It is the responsibility of those responsible for operational planning and run effective crisis management. To avoid severe crisis, the relations between going and staying secure organizations against threats and adverse events associated with crisis management is necessary. It is possible to lose credibility and their members with the crises in the private sector, corporate customers and non-profit organizations. Governments are also toiling incurred.

Companies that have crisis management plans are able to:

* Litigation and legal complaints to be prepared;

* Providing accurate and timely information on emergencies;

* Concerning for executives to minimize,

* Financial scandals control,

* The impact of critical events to minimize famous of an organization,

* Expertizing and commitment to deal with the crisis increase (Rezvani, 2008)

\subsection{Crisis management science and practice}

One of the major human professional is public service. All managers have duty endowment and to keep the environment dynamic and responsible for planning, design, where members of the missions and objectives of collaboration. In other words, managers have a responsibility to create opportunities and to the best in order to achieve its objectives and provide a healthy and safe environment.

\subsection{Crisis management features}

Crisis management features can be outlined as follows:

1. The voluntary participation of people in the State of Preparedness for disaster relief and mitigate the effects of natural disasters and crisis and encourage the reconstruction and normalization.

2. To be aware of affected people need.

3. The development of practical disaster preparedness are cared.

4. Gains productivity according to sympathetic to the needs of employees.

5. Philosophy that is based more times on people and leader values.

6. Do the things that has the best information and knowledge about them.

7. The organization is simple and with few staffs

8. Doing the things with proportionate and appropriate and decentralized.

9. Respects to local, social customs and a culture.

\section{Six Important Step in Crisis Management}

\subsection{Step one}

To Face with the crisis: facing a crisis, is addressing every step that is necessary to reduce the damage and losses caused by the crisis. Some organizations have already started to develop a crisis management plan that allows administrators to give a favorable response. Organizations that have not done so, are more likely to suffer losses because their managers have not developed a crisis management program. Managers must face and overcome the crisis. They should measure the need and support of the people and valuable assets, including intangible assets such as goodwill and image of it. More importantly, they should be confronting the crisis with courage, determination and react with commitment, dignity and perseverance. Good crisis management can greatly facilitate in disaster response and relief from danger. Unfortunately, poor managers may not understand the crisis and their organizations are at greater risk. An example of this is the crisis of Coca-Cola in Belgium in 1999. 


\subsection{Step two}

Re-thinking: after checking a crisis through the face of it, the manager for compensation requires mental fatigue caused by this pressure and need a rest. But this should not delay too long. This pause and rest is an opportunity for managers to find answers to the following questions:

1 - What happened and how?

2- What is the cause of this incident?

3 - Why is this happens?

In terms of learning, reflection is actually sympathetic to understand the mistakes of the past and find a better way and avoid mistakes in the future reference. Damage caused by the crisis should be thoroughly evaluated to determine the importance and negative effects for the organization. Such an assessment could result often ignore important lessons about crisis management. In an organization that runs crisis management program in response to the crisis, rethinking meant to look deep into crisis management program to re-test its effectiveness. Look for areas of vulnerability that may not be explored or completely removed, can be specified in crisis management program. Rethinking to address these issues, are the basis and foundation for the effort needed to strengthen institutional capacities in learning and prevent the crisis.

\subsection{Step Three}

Modernization program: If managers do not believe in the principle of continuous improvement, re-examine draws their attention to organizational readiness before the crisis. So after re-repair methods the next logical step should be carried out. If there is no crisis management plan, of course, must be added to the toolbox management. It is possible that some formidable opponents in the organization before the crisis, insist on the introduction of a formal crisis management plan. On the other hand, if you already have a crisis management plan, rethinking should be taken into account lessons learned from the crisis that has been over. Methods of modernization program requires that managers and colleagues who have common idea of continuous improvement, change and play the role of defender. If managers play this role well, and work colleagues and other partners (opponents) provide and make positive changes as a result of these positive changes, the organization will be stronger and less vulnerable.

\subsection{Step Four}

A sense of crisis: the main objective of sense is finding early signs of a potential crisis. In fact, this step is under consideration of internal and external environment of an organization. Analysis of strengths, weaknesses, opportunities and threats to public scrutiny and recognize the alarming trends may threaten the organization and will help. Although predicting a crisis is not an exact science, but should be considered as an essential part of planning of an organization's crisis. Feeling more accurately predict the crisis in the sense that it is necessary. In addition, administrators can increase the other two methods to successfully embody the sense of crisis. In the first method, they may wish to stroll through management techniques to run. This allows closer contact with other people in the organization. Talking and listening to the conversations of subordinates and colleagues, particularly those who work on the front line (such as sales staff), provide more and better ideas about different crisis scenarios may be managers' encounter in an organizations. The second valuable way is the network working. When managers participate more fulfilling Affairs and create more cooperation, they can enjoy the benefits of increased access to valuable information.

\subsection{Step Five}

Intervention and acting: Feel and understand the signs of crisis at a time when early signs of risk is so well known that cannot be overlooked, and administrators may be forced to intervene. A review of these symptoms, consult with experts and risk assessment of all relevant factors to ensure that these symptoms can lead to crisis, that is important for managers. Obviously, the perception and analysis of managers in achieving the final result is of utmost importance. If managers are confident that intervention is a good way, to quickly and timely intervention strategy intended to implement. The best strategy is to inhibit the growth of a crisis and its potential to radically curb. If crises are not restrained, although in the early stages of formation, they desire to develop and so increases that are uncontrollable and deadly. Intervention is certainly a step in crisis management problem. Although intervention is a necessary step, if managers want their organizations for quickly escape from the trap of a crisis spreading liked, basically the more resources will be needed to overcome. 


\subsection{Step Six}

The ultimate act of last resort in the face of the crisis: people who are close to the river are often associated with rebellion, live, and are familiar with sandbags as flood control methods. Also, when the intervention is not able to contain the initial crisis, as a last resort should benefit from all the facilities. All sources of support (auxiliary) of personnel and equipment must be on the alert (Tolaee, 2008).

\section{Conclusion}

Corporate crisis management is as a systematic process that has the potential to identify and predict crises during the process of trying. Then in front of them take preventive measures to minimize its impact. It is clear that managers cannot be prepared against all types of crisis. However, if they are to crisis management as an integral part of their strategic management responsibility, the possibility is that the crisis is greatly reduced organizations. According to crisis management and its relation to the technical and operational planning is very important.

\section{References}

Saveh doroodi Mostafa. (2011). Organizational strategies and crisis management, Tehran, Faculty of Farabi Science and Technology press.

Heidari et al. (2002). A new approach to organization and management theories in today world, Tehran, publisher of Fara shenakht Andisheh.

Jahanian Ramezan. (2010). Modern theories of organization and management, Tehran, Payame Sama publication.

Nasehifar Vahid. (2001). Concepts and tips on crisis management, Tehran, Bonyad Janbazan publication.

Hejazi Syed Shahabuddin. (2009). Passage of the crisis, the monthly of Tadbir twentieth year, 206, 45-49.

Qoli Sanam Allah. 2014. Ten Tips to guide functional out of the crisis, monthly of Tadbir, 25(264), 30-32.

Soltani far Mohammad, Mortazavi Mahmoud Reza. (2009). Optimal model of media organizations in crisis management, editorial, 44, 35-46.

Daft Richard Wall. (2002). Theoretical and organizational design, translation and Muhammad Ali Parsanian Arabs, Tehran, Cultural Research Bureau.

Heidari et al. (2002). A new approach to organization and management theories in the world today, Tehran, publisher of meta-cognitive thoughts.

Hosseini Sayed Yaqub. (2012). Evaluation of strategic management influence on the quality of crisis management operations, Journal of research, 2, 77-85.

Armstrong, A, Folr, P. (2003). "Foundations for a learning organization: organization learning mechanisms ", the learning organization, $10,3$.

Egan TM, Yang B, Bartlett K. (2004). The effects of organizational learning culture \& amp; job satisfaction on motivation to transfer learning \&amp; turnover intention ", human resource development quarterly, 15(3), 5-12.

Gloet, Marianne, Mike, Berrell. (2003). "The dual paradigm nature of knowledge management: implications for achieving quality outcomes in human resource management", Journal of knowledge management, 7(1), 8-13. 